\title{
EFEITO DE DIFERENTES PORTA-ENXERTOS NO VIGOR E PRODUTIVIDADE DA LARANJEIRA 'PERA' (Citrus sinensis L.) Osbeck)
}

FRANCISCO DE ASSIS ALVES MOURÃO FILHO ${ }^{1}$ MARTHA MARIA MISCHAN ${ }^{2}$ ARY APPARECIDO SALIBE ${ }^{3}$

RESUMO: O presente trabalho teve como objetivo avaliar a influência de oito porta-enxertos no vigor, produção e produtividade da laranjeira 'Pera'. Para a realização deste estudo utilizaram-se plantas de um experimento instalado na Fazenda Experimental Lageado da UNESP, Campus de Botucatu, São Paulo. O delineamento estatístico adotado foi o de blocos ao acaso. Os porta-enxertos estudados foram: limoeiros 'Cravo', 'Volkameriano' e 'Rugoso da Flórida', tangerineiras 'Cleópatra' e 'Sunki', laranjeira 'Caipira', 'Trifoliata' e citrange 'Carrizo'. os resultados revelaram que os porta-enxertos tangerineiras 'cleópatra' e 'Sunki' e limoeiro 'Rugoso da Flórida' induziram a um maior desenvolvimento das plantas da laranjeira 'Pera'. Os porta-enxertos 1 imoeiros 'Volkameriano', 'Rugoso da Flórida' e 'Cravo' e as tangerineiras 'Sunki' e 'Cleópatra' induziram as maiores pro-

1 Professor Assistente, Departamento de Horticultura da ESALQ/USP-13400 - PIRACICABASP.

2 Professora Assistente Doutora - Departamento de Bioestatistica - IB / UNESP - 18600 BOTUCATU-SP.

3 Professor Titular - Departamento de Horticultura - FCA/UNESP - 18600 - BOTUCATU-SP. 
duções totais. Os maiores valores de indice de eficiência (produção $(\mathrm{kg}) / \mathrm{m}^{3}$ copa) foram constatados em plantas sobre 'Trifoliata', citrange 'Carrizo' e limoeiro 'Cravo'. Características desses porta-enxertos são discutidas.

Termos para Indexação: citros, porta-enxertos, propagação.

\section{EFFECT OF DIFFERENT ROOTSTOCKS IN THE PLANT VIGOR AND YIELD OF 'PERA' SWEET ORANGE (Citrus sinensis, (L.) Osbeck)}

ABSTRACT: The present study was carried out aiming to determine the effect of different rootstocks in plant vigor and yield of 'Pera' sweet orange, Citrus sinensis, (L.) Osbeck. The research work was conducted in plants of a rootstock experiment, established at Lageado Experimental Farm, UNESP, Botucatu, state of São Paulo. The eight rootstocks studied were: 'Rangpur' lime (Citrus limonia, (L.) osbeck); 'Volkamer' lemon (Citrus volkameriana, Pasquale); 'Florida rough' lemon (Citrus jambhiri, Lushington); 'Cleopatra' mandarin (Citrus reshni, hort. ex. Tanaka); 'Sunki' mandarin (Citrus sunki, hort. ex. Tanaka); 'Caipira' sweet orange (Citrus sinesis (L.) Osbeck); 'Trifoliata' orange (Poncirus trifoliata, Rasfinesque) and 'Carrizo' citrange (Citrus sinensis $x$ Poncirus trifoliata). The results showed that 'Cleopatra' and 'Sunki' mandarins and 'Florida' rough lemon induced the greatest plant vigor. The rootstocks 'Volkamer' lemon, 'Florida' rough lemon, 'Rangpur' lime and 'Sunki' and 'Cleopatra' mandarins induced the greatest total yields. The greatest values of eficiency index (yield $(\mathrm{kg}) / \mathrm{m}^{3}$ canopy volume) were obtained in plants budded on 'Trifoliata' orange, 'Carrizo' citrange and 'Rangpur' lime. Characteristics of these rootstocks are discussed.

Index Terms: citrus, rootstocks, propagation. 


\section{INTRODUÇĀO}

Atualmente, a quase totalidade dos pomares cítricos do planalto paulista está apoiada em apenas um porta-enxerto, o limoeiro 'Cravo'. Isto decorre do fato desse portaenxerto ser bastante vigoroso no viveiro e induzir à formação de plantas vigorosas, de produção precoce e resistente a seca, entre outras vantagens.

Por outro lado, a citricultura paulista tem corrido um grande risco estando apoiada em apenas um porta-enxerto. A anormalidade 'declínio' das plantas citricas, de causa ainda desconhecida, vem afetando combinações enxertadas em limoeiro 'Cravo'. Anualmente, 4 a 5 milhões de plantas citricas são substituídas nos pomares do Estado devido ao declínio.

Nos novos plantios segue como variedade copa preferida a laranjeira 'Pera', mas enxertada em diferentes porta-enxertos. São necessários, portanto, novos estudos que avaliem o comportamento desta copa, de grande valor econômico, sobre diferentes cavalos.

VASCONCELLOS (1939), no Brasil, realizou um dos trabalhos pioneiros nessa área, estudando o comportamento da laranjeira 'Bahia comum' sobre cinco diferentes porta-enxertos. A seguir diversos autores investigaram a influência do porta-enxerto no vigor e produtividade dos citros, destacando-se os trabalhos em laranjeira 'Pera' de MOREIRA (1941, 1946), BRIEGER \& MOREIRA (1945), MOREIRA et alii $(1960,1865)$, PASSOS et alii (1975), TEÓFILO SOBRINHO et alii (1984, 1986, 1986a), GENU et alii (1981) e TRINDADE et alii (1987).

o presente trabalho teve como objetivo avaliar o efeito de oito diferentes portaenxertos no vigor, produção e produtividade de laranjeira 'Pera'. 


\section{MATERIAL E MÉTODOS}

o estudo foi realizado em plantas de experimento instalado na Fazenda Experimental Lageado, pertencente à Faculdade de Ciências Agronômicas - UNESP, Campus de Botucatu-São paulo. o ensaio foi instalado em novembro de 1981, em espaçamento de $4 \times 4 \mathrm{~m}$.

Para a formação das mudas do pomar experimental, todas as gemas foram obtidas de uma única planta de laranjeira 'Pera' clone pré-imunizado contra a virose tristeza do Banco de Germoplasma de Citros do Instituto Agronômico de Campinas, Estado de São Paulo. As sementes dos porta-enxertos foram coletadas no Banco de Germoplasma de Citros de Fazenda Experimental Lageado. Os porta-enxertos estudados foram: Limoeiro 'Cravo' (Citrus Iimonia, (L.) Osbeck); laranjeira 'Caipira' (Citrus sinesis (L.) Osbeck): 'Trifoliata' (Poncirus trifoliata, Rasfinesque); tangerineira 'Cleopatra' (Citrus reshni, hort. ex. Tanaka); tangerineira 'Sunki' (Citrus sunki, hort. ex. Tanaka); limoeiro 'Volkameriano' (Citrus volkameriana, Pasquale); limoeiro 'Rugoso da Florida' (Citrus jambhiri, Lushington); e citrange 'Carrizo' (Citrus sinensis $\mathrm{x}$ Poncirus trifoliata).

Testes para as diversas viroses, efetuados nas plantas do experimento, revelaram apenas a presença de uma estirpe fraca do virus da tristeza, confirmando o carăter préimunizado do clone para essa virose.

o del ineamento experimental utilizado foi 0 de blocos ao acaso com 8 tratamentos (porta-enxertos), duas plantas por parcela e 4 repetições.

Os tratos culturais foram uniformes para todas as plantas do experimento. O controle de plantas daninhas fêz-se através de gradeações, capinas mecânicas e manuais, quando necessário. 
As plantas do experimento sofreram três pulverizaçōes de Dicofol (Kelthane) na concentração de $200 \mathrm{ml}$ (p.c.)/100 litros de água, nos meses de março e abril de 1987 para controlar focos de ácaro da leprose (Brevipalpus phoenicis).

o ensaio foi conduzido sem irrigação. os dados de correção do solo e adubação encontram-se na Tabela 1 .

o vigor das plantas em março de 1927 foi avaliado através de dois parâmetros: circunferência do tronco a $10 \mathrm{~cm}$ acima do ponto de enxertia e volume da copa, calculado pela fórmula:

onde

$$
\mathrm{V}=2 / 3 \pi \mathrm{R}^{2} \mathrm{H}
$$
$V$ é o volume da copa $\left(\mathrm{m}^{3}\right)$
$R$ o raio médio da copa (m) e
$\mathrm{H}$ é a altura da planta (m)

- controle da produção das plantas foi realizado de 1984 a 1987 . Os dados da produção em quilos de frutos foram obtidos multiplicando-se o número de frutos (inclusive os da safra ("temporona") em cada parcela, pelo seu respectivo peso médio para cada variedade porta-enxerto e para cada ano. 
Tabela 1 - Épocas de aplicação e quantidades de adubos e corretivos empregados no experimento (em gramas por planta).

\begin{tabular}{|c|c|c|c|}
\hline \multicolumn{2}{|c|}{$\begin{array}{l}\text { Epoca de } \\
\text { aplicação }\end{array}$} & $\begin{array}{l}\text { Adubo ou } \\
\text { corretivo }\end{array}$ & $\begin{array}{l}\text { Dosagem } \\
\text { (g/planta }\end{array}$ \\
\hline $\begin{array}{l}1981 \\
\text { (aber } \\
\text { cova }\end{array}$ & $\begin{array}{l}1 \text { - julho } \\
\text { (tura das } \\
\text { as) }\end{array}$ & $\begin{array}{l}\text { Esterco de curral } \\
\text { Superfosfato simples }\end{array}$ & 201 \\
\hline 1982 & - novembro & $\begin{array}{l}\text { Sulfato de amônio } \\
\text { Superfosfato simples } \\
\text { cloreto de potássio }\end{array}$ & $\begin{array}{r}50 \\
1000 \\
300\end{array}$ \\
\hline 1983 & - agosto & $\begin{array}{l}\text { Sulfato de amônio } \\
\text { Superfostato simples } \\
\text { cloreto de potássio }\end{array}$ & $\begin{array}{r}1000 \\
1500 \\
300\end{array}$ \\
\hline 1985 & - setembro & $\begin{array}{l}\text { Calcário } \\
\text { Sulfato de amônio } \\
\text { Superfosfato simples } \\
\text { Cloreto de potássio }\end{array}$ & $\begin{array}{l}5000 \\
1000 \\
1500 \\
300\end{array}$ \\
\hline 1986 & $\begin{array}{l}\text { - junho } \\
\text { - setembro } \\
\text { - novembro }\end{array}$ & $\begin{array}{l}\text { Calcário } \\
4-14-08 \\
\text { Nitrocálcio }\end{array}$ & $\begin{array}{l}5000 \\
1500 \\
1000\end{array}$ \\
\hline 1987 & - fevereiro & Nitrocálcio & 500 \\
\hline
\end{tabular}

o efeito dos diferentes porta-enxertos na produtividade da laranjeira 'Pera' foi avaliado no referente à produção em quilos de frutos por metro cúbico de copa. Estes dados foram calculados dividindo-se a produção em quilos de frutos por planta, em 1987, pelo volume da copa, em metros cúbicos. Os valores obtidos denominaram-se Indice de Eficiência. 
O efeito dos porta-enxertos na qualidade dos frutos da laranjeira 'Pera' também foi estudado e será motivo para um próximo trabaIho.

\section{RESULTADOS E DISCUSSĀO}

Os dados de circunferência média dos troncos e volume médio das copas das árvores de laranjeira 'Pera' enxertadas nos oito porta-enxertos encontram-se na Tabela 2. Pelos dados dessa tabela nota-se que os maiores valores de circunferência do tronco foram encontrados nas plantas enxertadas nas tangerineiras 'Cleópatra' e 'Sunki', sem diferirem estatisticamente das plantas sobre limoeiros 'Cravo', 'Volkameriano' e 'Rugoso da Flórida'. Os menores valores foram registrados em plantas enxertadas em 'Trifoliata' e citrange 'Carrizo'. Esses resultados confirmam os já obtidos por outros autores que estudaram o efeito dos diferentes porta-enxertos na circunferência do tronco da laranjeira 'Pera', tais como BRIEGER \& MOREIRA (1945) e MOREIRA et alii (1960). Entretanto, os resultados obtidos por GENÚ et alii (1981) discordam dessa pesquisa, pois, apesar do limoeiro 'Cravo' ter induzido a grandes perímetros de tronco de plantas de laranjeira 'Pera', não diferiu estatisticamente dos resultados obtidos em dois híbridos de 'Trifoliata' e do citrumelo '445-70/133'.

Em relação ao volume da copa, Tabela 2 , os maiores valores foram obtidos nas plantas sobre tangerina 'Sunki' e limoeiro 'Rugoso da Flórida', sem contudo diferirem das plantas sobre tangerina 'Cleópatra' e limoeiro 'Volkameriano'. Igualmente ao constatado para a circunferência do tronco, os menores volumes de copa foram registrados nas plantas enxertadas em 'Trifoliata' e citrange 'Carrizo'. Esses resultados concordam com os obtidos por TÉ́fILO 
SOBRINHO et alii $(1984,1986,1986 a)$ e TRINDADE et alii (1987).

No referente à produção, a primeira colheita do ensaio foi realizada em 1984 e resultou em uma quantidade muito pequena de frutas, devido à pouca idade das plantas. Em decorrência, não foi realizada a análise estatistica dos dados de produção de 1984 . Entretanto, esses dados indicam diferenças na precocidade de produção induzida pelos portaenxertos. Os dados totais para 1984 estão reunidos na Tabela 3. As médias de produção, em quilos de frutos por planta, nos anos de 1985, 1986, 1987, e a produção total do período para cada porta-enxerto encontram-se na Tabela 4. Pelo dados dessa tabela, nota-se que, em 1985, o porta-enxerto que induziu as maiores produçōes foi o limoeiro 'Cravo', sem contudo, diferir estatisticamente dos porta-enxertos limoeiros 'Volkameriano' e 'Rugoso da Flórida'. As plantas sobre laranjeira 'Caipira' não produziram uma fruta sequer, sendo as menos precoces, não diferindo estatisticamente das plantas sobre tangerineiras 'Cleópatra' e 'Sunki', citrange 'Carrizo' e 'Trifoliata'.

Para o ano de 1986, os porta-enxertos limoeiro 'Volkameriano' e 'Rugoso da Flórida' induziram as maiores produçōes em quilos de frutos por planta, sem diferirem estatisticamente dos porta-enxertos limoeiro 'Cravo' e tangerineiras 'Sunki' e 'Cleópatra'. As plantas menos produtivas foram, novamente, aquelas sobre laranjeira 'Caipira', sem diferirem estatisticamente daquelas sobre citrange 'Carrizo' e 'Trifoliata'. 
Tabela 2 - Circunferências médias dos troncos e volumes médios das copas de laranjeira 'Pera' enxertadas em oito porta-enxertos.

\begin{tabular}{|c|c|c|c|}
\hline $\begin{array}{l}\text { Porta- } \\
\text { enxertos }\end{array}$ & $\begin{array}{l}\text { Circunferência } \\
\text { Média (cm) }\end{array}$ & Volum & 3) Médio \\
\hline LCR & $38,88 \mathrm{ab}$ & 8,11 & bcd \\
\hline CAI & $35,15 \quad b c$ & 6,10 & $c d$ \\
\hline TRI & 26,13 & 4,00 & d \\
\hline CLE & 46,25 a & 12,82 & $a b$ \\
\hline SUN & 49,75 a & 15,36 & a \\
\hline VOL & $43,75 \mathrm{ab}$ & 11,59 & $a b c$ \\
\hline RUG & $45,88 \mathrm{ab}$ & 15,83 & a \\
\hline CAR & 25,00 & 5,20 & $d$ \\
\hline $\mathrm{X}$ & 39,29 & 10,02 & \\
\hline C.V. (\%) & 11,69 & 25,77 & \\
\hline
\end{tabular}

Obs: Médias seguidas da mesma letra não diferem entre si ao nivel de 5\% de probabilidade, pelo Teste de Tukey. 
Tabela 3 - Produções totais de laranjeiras 'Pera' (em número de frutos) enxertadas em oito porta-enxertos para o ano de 1984.

\begin{tabular}{cc}
\hline Porta-enxertos & Produção Total \\
\hline LCR & 75 \\
CAI & 0 \\
TRI & 19 \\
CLE & 11 \\
SUN & 3 \\
VOL & 162 \\
RUG & 1 \\
CAR & 1 \\
\hline
\end{tabular}


Tabela 4 - Produçōes médias, por planta, em quilogramas de frutos de laranjeiras 'Pera' sobre oito porta-enxertos, em $1985,1986,1987$ e produção total média.

\begin{tabular}{|c|c|c|c|c|}
\hline $\begin{array}{l}\text { Porta- } \\
\text { enxertos }\end{array}$ & 1985 & 1986 & $\begin{array}{l}0_{1987} \\
\end{array}$ & Total \\
\hline LCR & $21,993 a$ & $70,585 \mathrm{ab}$ & $42,465 \mathrm{bc}$ & $135,043 \mathbf{a}$ \\
\hline CAI & d & $5,340 \quad \mathrm{~d}$ & 19,590 & 24,930 \\
\hline TRI & $5,778 \mathrm{bcd}$ & $30,380 \mathrm{bcd}$ & $27,715 \mathrm{~cd}$ & $63,873 \mathrm{bcd}$ \\
\hline CLE & 0,553 & $45,915 \mathrm{abc}$ & $48,013 \mathrm{ab}$ & $94,480 a b c$ \\
\hline SUN & $4,540 \quad \mathrm{~cd}$ & $61,743 \mathrm{abc}$ & $62,678 \mathbf{a}$ & $128,960 \mathrm{ab}$ \\
\hline VOL & $21,743 \mathrm{ab}$ & $90,310 a$ & 38,960 bc & $151,013 a$ \\
\hline RUG & $14,768 \mathrm{abc}$ & $84,885 a$ & $42,718 \mathrm{bc}$ & $142,370 \mathbf{a}$ \\
\hline CAR & 1,090 & 21,180 & 30,613 & 52,883 \\
\hline$x$ & 9,057 & 52,264 & 39,367 & 100,688 \\
\hline C.V. (\%) & 36,14 & 20,62 & 9,23 & 14,97 \\
\hline
\end{tabular}

Obs: Médias seguidas da mesma letra não diferem entre si ao nivel de $5 \%$ de probabilidade, pelo Teste de Tukey. 
Em 1987, as plantas que apresentaram as maiores produções em quilos de frutos por planta foram aquelas enxertadas em tangerineira 'Sunki', sem diferirem das plantas sobre tangerineira 'Cleópatra', ao nível de 5\% de probabilidade. o porta-enxerto laranjeira 'Caipira' induziu as menores produções neste ano, sem diferir do 'Trifoliata' e citrange 'Carrizo'. As plantas sobre os limoeiros 'Rugoso da Flórida', 'Cravo' e 'Volkameriano' apresentaram produçōes intermediárias.

Uma análise da produção conjunta dos três primeiros anos do experimento é muito importante, pois, aponta não só os porta-enxertos que induziram a maior produção, mas também a uma maior precocidade. Pelos dados da Tabela 4, constata-se que os porta-enxertos que induziram às maiores produções em quilos de frutos por planta no período estudado (1985 a 1987) foram os 1 imoeiros 'Volkameriano', 'Rugoso da Flórida' e 'Cravo, sem diferirem significativamente dos porta-enxertos tangerineiras 'sunki' e 'Cleópatra'. O porta-enxerto laranjeira 'Caipira' induziu às menores produçōes no período estudado, sem diferir significativamente dos porta-enxertos citrange 'Carrizo' e 'Trifoliata'.

Os resultados dessa pesquisa concordam em parte com os obtidos por PASSOS et alii (1976), onde as maiores produções totais de laranjeira 'Pera' nos primeiros anos de ensaio foram obtidas em plantas sobre tangerineira 'Cleópatra' e limoeiros 'Cravo' e 'Rugoso da Flórida'. Da mesma forma, os estudos realizados por TÉ́FILO SOBRINHO et alii (1986, 1986a) confirmaram a menor produção induzida pelo porta-enxerto 'Trifoliata'. TRINDADE et alii (1987) também apontam o limoeiro 'Rugoso da Flórida' como porta-enxerto que induziu às maiores produçôes em laranjeira' 'Pera' em seus ensaios. 
Por outro lado, TEÓFILO SOBRINHO et alii (1984) não constataram diferenças significativas na produção de laranjeira 'Pera' sobre onze porta-enxertos em um período de seis anos. os valores médios do índice de eficiência das plantas de laranja 'Pera' calculados para cada porta-enxerto encontram-se na Tabela 5. Pelos dados desta tabela, nota-se que o 'Trifoliata' induziu os maiores valores de índice de eficiência em laranjeira 'Pera', não diferindo dos porta-enxertos limoeiros 'Cravo' e citrange 'Carrizo', ao nível de 5\% de probabilidade. As plantas sobre limoeiro 'Rugoso da Flórida' apresentaram os menores valores de indice de eficiência, sem diferirem estatisticamente das plantas sobre limoeiro 'Volkameriano' e laranjeira 'Caipira' e as tangerineiras 'Sunki' e 'Cleópatra'.

- motivo pelo qual as plantas de laranjeira 'Pera' sobre 'Trifoliata' terem apresentado os maiores valores de índice de eficiência reside no fato deste porta-enxerto induzir à formação de plantas com baixo volume de copa mas bastante produtivas, o que já foi constatado por MOREIRA et alii (1960), estudando a produtividade de diversas variedades cítricas, incluindo a laranjeira 'Pera'. O inverso aconteceu com as plantas enxertadas em limoeiro 'Rugoso da Flórida' que, apesar de apresentarem os maiores volumes de copa (Tabela 2), não atingiram boa produção por unidade de volume.

A superioridade do 'Trifoliata' na indução de maiores volumes de Indice de eficiência em citros também foi constatada por diversos autores, entre eles: STADEN \& OBERHOLZER (1977); CRESCIAMANNO et alii (1981) e TEÓFILO SOBRINHO et alii $(1986,1986 a)$. Esta pesquisa confirma mais uma vez este resultado, indicando o 'Trifoliata' como porta-enxerto promissor para a produção de plantas de pequeno porte, redução no espaçamento e aumento da 
produção por área. Entretanto, deve-se ressaltar a forte incompatibilidade existente entre - porta-enxerto 'Trifoliata' e a laranjeira 'Pera' com a formação de uma linha de goma na região do ponto de enxertia, fato este constatado neste ensaio após o $7^{\circ}$ ano e que confirma os dados obtidos por SALIBE (1961) e por TEÓFILO SOBRINHO et alii (1984). Por este motivo, os pomares de laranja 'Pera' sobre 'Trifoliata', apesar de produtivos, terão longevidade menor, não sendo esta combinação recomendada para cultivos comerciais (exceto usando-se um "inter-stock").

Não foram constatados sintomas de incompatibilidade nas plantas enxertadas nos demais porta-enxertos. Estes dados são diferentes dos obtidos por TEÓFILO SOBRINHO et alii (1984) onde foram observados sinais de incompatibilidade moderada nas plantas de laranja 'Pera' sobre limoeiro 'Rugoso da Flórida' e limoeiro 'Volkameriano'.

Até o final da coleta dos dados, as plantas do experimento não apresentavam sintomas da anormalidade "declínio", a qual os autores consideram não ser causada por agente patogênico.

Entretanto, sabe-se que as combinaÇões de laranjeira 'Pera' com as tangerineiras 'Cleópatra' e 'Sunki' e com a laranjeira 'Caipira' não têm apresentado os sintomas do declínio, em condições de campo. 


\section{CONCLUSŌES}

1. As tangerineiras 'Cleópatra' e 'Sunki' e limoeiro 'Rugoso da Flórida' induziram um maior desenvolvimento das plantas de laranjeira'Pera' produzindo árvores com maior circunferência de tronco e grandes volumes de copa. Por outro lado, os porta-enxertos 'Trifoliata' e citrange 'Carrizo' induziram a formação de árvores siggnificativamente menores.

2. Os limoeiros 'Volkameriano', 'Rugoso da Flórida' e 'Cravo' e as tangerineiras 'sunki' e 'Cleópatra', induziram as maiores produçōes totais no experimento enquanto que as plantas de laranjeira 'Pera' sobre laranjeira 'Caipira', citrange 'Carrizo' e 'Trifoliata' apresentaram as produções mais baixas no período estudado.

3. Os limoeiros 'Cravo', 'Rugoso da Flórida' e 'Volkameriano' induziram precocidade de produção, enquanto que os porta-enxertos laranjeira 'Caipira', 'Trifoliata' e citrange 'Carrizo'retardaram a entrada das plantas em produção.

4. Os maiores valores de índice de eficiência (produção de frutos $(\mathrm{kg}) / \mathrm{m}^{3}$ de copa) foram constatados em plantas sobre 'Trifoliata', citrange 'Carrizo' e limoeiro 'Cravo'.

5. Os porta-enxertos tangerineira 'sunki' e tangerineira 'Cleópatra' são os mais indicados para a diversificação do limoeiro 'Cravo' como porta-enxerto para laranjeira 'Pera'. 


\section{AGRADECIMENTOS}

- primeiro autor agradece o apoio da Fundação de Amparo à Pesquisa do Estado de São paulo (FAPESP) que the concedeu bolsa de mestrado, tornando possível a realizaçāo deste trabalho.

\section{REFERÊNCIAS BIBLIOGRÁFICAS}

BRIEGER, F.G. \& MOREIRA, S. Experiências de cavalos para citrus. II. Bragantia, Campinas, $\underline{5}$ (10): 597-658, out. 1945 .

CRESCIMANNO, F.G.; DEIDDA, P. ; FRAU, A.M. Citrus rootstock trials in sardinia: preliminary results on the performance of ten rootstocks for Navel and Valencia oranges and for Marsh grapefruit. Proceedings of the International Society of citriculture, Tokyo, 1: 119-23, 1981.

GENÚ, P.J. de C.; PINTO, A.C. de Q.; MATTOS, J.K. de A. Informações preliminares sobre - comportamento de seis porta-enxertos para laranjeira 'Pera' (Citrus sinensis, (L.) osbeck) cultivados nos cerrados do Distrito Federal. In: CONGRESSO BRASILEIRO DE FRUTICULTURA, 6, Recife, 1981. Anais... Recife, Sociedade Brasileira de Fruticultura, 1981, V.4, p.1738-85.

MOREIRA, S. Experiências de cavalos para citrus I. Bragantia, Campinas, 1(8/9):52565, ago./set. 1941 .

MOREIRA, S. Cavalos para citros em São Paulo. Revista da Agricultura, Piracicaba, 21 (56) :206-26, 1946 . 
MOREIRA, S.; OLIVEIRA, V.G.; ABRAMIDES, E. Experimentos de cavalos para citrus III. Bragantia, Campinas, 19(59): 961-95, nov. 1960 .

MOREIRA, S.; SALIBE, A.A.; OLIVEIRA, V.G.; ABRAMIDES, E. Experimentos de cavalos para citrus V. Ciência e Cultura, são Paulo, 17 (2): 190-1, 1965 .

PASSOS, O.S.; CUNHA SOBRINHO, A.P.da; COELHO, $\mathrm{Y}$. da S. Porta-enxertos para laranjeira Pera, Citrus sinensis (L.) Osbeck. In: CONGRESSO BRASILEIRTO DE FRUTICULTURA, 3, Rio de Janeiro, 1975. Anais.... Campinas, Sociedade Brasileira de Fruticultura, 1976, v.1, p.91-8.

SALIBE, A.A. Scion-rootstock incompatibilities in Brazil. In: Proc. 2nd Conf. Intern. organization Citrus Virol. Gainesville Univ. Flórida Press. p.172-6, 1961.

STADEN, D.F.A. von. \& OBERHOLZER, P.C.J. The performance of nucellar citrus lines on several rootstocks in south Africa. Proceedings of the International Society of Citriculture, Flórida, 2:532-4, 1977.

TEÓFILO SOBRINHO, J.; POMPEU JUNIOR, J.; FIGUEIREDO, J.O. de; BARBIN, D. ; DEMETRIO, C.G.B. Competição de onze porta-enxertos para laranja Pera, Citrus sinensis (L.) Osbeck. In: CONGRESSO BRASILEIRO DE FRUTICULTURA, 7, Florianópolis, 1983. Anais. Florianópolis, Sociedade Brasileira de Fruticultura / Empresa Catarinense de PesPesquisa Agropecuária S.A. 1984, p.581-91. 
TEÓFILO SOBRINHO, J ; POMPEU JUNIOR, J .; FIGUEIREDO, J.O. de; BARBIN, D. ; JACON, J. R.; DEMETRIO, C.G.B. Porta-enxertos para laranja Pera, Citrus sinensis (L.) Osbeck. In: CONGRESSO BRASILEIRO DE FRUTICULTURA, 8, Brasilia, 1986. Anais ... Brasilia, Empresa Brasileira de Pesquisa Agropecuária/ Conselho Nacional de Desenvolvimento Cientifico e Tecnológico, 1986, V.1, p.117-21.

TEÓFILO SOBRINHO, J.; POMPEU JUNIOR, J.; FIGUEIREDO, J.O. de; JACON, J.R. Resultados de 11 anos de pesquisas de experimento de porta-enxertos para laranja Pera, clone premunizado. Laranja, Cordeirópolis, 1(7): 209-23, 1986a.

TRINDADE, J.; SILVA, L.M.S.; SILVA, J.V.B.; PASSOS, O. S.; CUNHA SOBRINHO, A. P. Behavior of Sweet orange clones on Rangpur lime $C$. Iimonia Osb. and Florida's Rough lemon C.jambhiri, Lush. Proceedings of the International Society of Citriculture, são Paulo, 1:45-7, 1987 .

VASCONCELLOS, P.W.C. de. Estudo comparativo da laranjeira "Bahia commun", sobre cinco diferentes "porta-enxertos". Boletim da Agricultura. São Paulo, 40:587-621, 1939.

Trabalho entregue para publicação em 01.06 .90 Trabalho aprovado para publicação em 17.04.91 